\title{
HP: um modelo aprimorado de armadilha luminosa de sucção para a captura de pequenos insetos
}

\author{
HP: an improved model of sucction light trap \\ for the capture of small insects
}

\author{
Hoover Pugedo ${ }^{1}$, Ricardo A. Barata ${ }^{2}$, João Carlos França-Silva ${ }^{3}$, \\ Jaime C. Silva ${ }^{4}$ Edelberto S. Dias ${ }^{2}$
}

\begin{abstract}
RESUM0
Descreve-se um novo tipo de armadilha, resultado do aprimoramento de um modelo muito utilizado, conhecido como CDC. Anova armadilha, denominada HP, apresenta como vantagens alta eficiência, facilidade no manuseio e transporte, além de ser confeccionada quase que exclusivamente com material nacional, o que reduz consideravelmente seu custo final.
\end{abstract}

Palavras-chaves: Captura de insetos. Armadilha luminosa. HP.

\begin{abstract}
This paper describes a new model of light trap, named HP, based on the widely used CDC trap. Its advantages include high efficiency, easy handling and transport. Moreover, it is almost totally made of national materials, which reduces considerably the final cost.
\end{abstract}

Key-words: Capture of insetcs. Light trap. HP.

Diversos tipos de armadilhas luminosas tem sido desenvolvidos para auxiliar na captura de insetos de pequeno porte em estudos de campo ${ }^{1234}$.

Descrição da armadilha. Caracteriza-se por um corpo em formato cilíndrico, construído em termoplástico, PVC ou resina de alta resistência de cor branca, em cuja porção superior está situada uma tela protetora, projetada em forma convexa. A fonte de luz, especialmente montada em terminal tipo baioneta, é constituída por uma lâmpada do tipo tubular, de baixo consumo, que emite radiação luminosa de alta intensidade, com temperatura de emissão entre 2000 a 3000 graus Kelvin. 0 posicionamento da lâmpada proporciona cobertura extensa e eficiente da área de captura, atraindo os insetos presentes nos arredores ( Figura 1).

A fonte de energia, composta por quatro pilhas de 1,5 volts ( tipo D) , alimenta um micro-motor de baixa rotação (1400rpm) que, por sua vez, aciona uma hélice. A conformação estreitada das pás na área central da hélice, em relação às bordas, associada à rotação adequada do motor forma um sistema de exaustão de ar, capaz de succionar os insetos vivos e íntegros, aprisionandoos dentro de um saco coletor (Figura 1).

As calhas isolantes de PVC e os suportes de pilhas são sustentadas nos lados externos dos braços laterais por uma barra de aço inox, dobrada em forma de U. 0 corpo da máquina, na sua face interna, possui um parafuso central que serve de suporte para assentamento do prato de proteção. Nos braços da barra de suporte, existem duas caixas para suporte das pilhas, montadas com uma calha de PVC, que funciona como isolante ( Figura 1).

Um prato protetor com um ilhós de aço cromado, revestindo 0 furo de fixação central, recebe 0 parafuso central da barra de sustentação e fixação. Seu perfil côncavo e polido na sua superfície inferior possibilita a reflexão da luz sobre o corpo da máquina e 0 saco coletor, que à noite se destaca como um corpo

1. HP Biomédica, Sabará, MG. 2. Centro de Pesquisas René Rachou da Fundação Oswaldo Cruz, Belo Horizonte, MG. 3. Universidade Federal de Minas Gerais, Belo Horizonte, MG. 4. Fundação Nacional de Saúde, Belo Horizonte, MG.

Endereço para correspondência: Dr. Edelberto Santos Dias. Laboratório de Leishmanioses/CPqRR. Av. Augusto de Lima 1715, Barro Preto 30190-002 Belo Horizonte, MG, Brasil.

Fax 553132953566 ramal 158

e-mail: edel@ cpqrr.fiocruz.br

Recebido para publicação em 5/4/2004

Aceito em 17/9/2004 


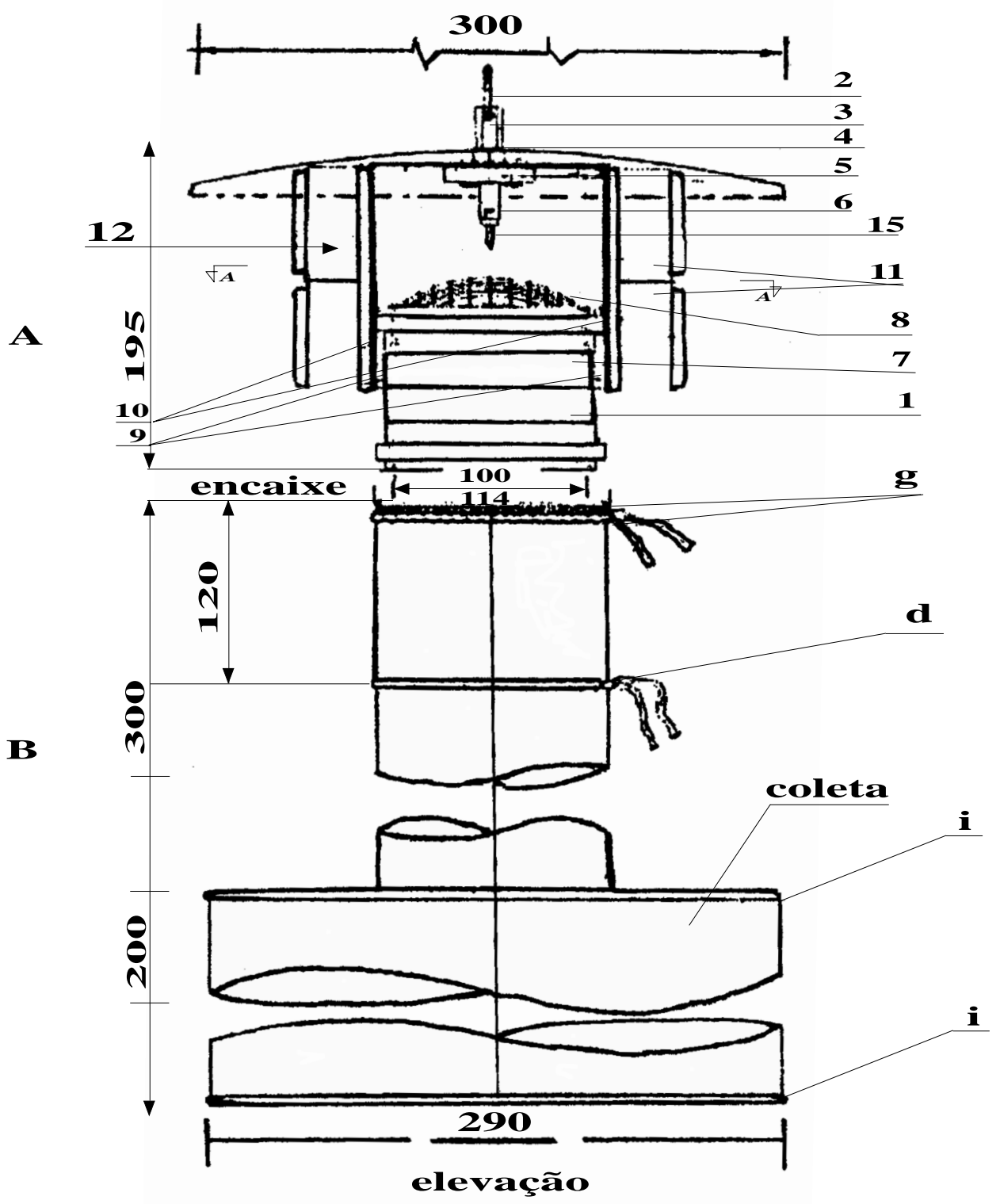

Figura 1 - Conjunto A - Corpo da armadilha, composto de: 1-Carenagem inferior; 2-Argola movel de fixação do prato e sustentação do conjunto; 3-Pino de fixação do prato; 4- Prato de proteção com superfície inferior côncava e polida; 5 -Suporte isolante para o soquete para a lấmpada; 6-Soquete para a lâmpada; 7-Carenagem superior; 8-Tela de proteção côncava; 9-Calços de alinhamento dos braços da barra de fixação e suporte; 10-Braços da barra de fixação e suporte; 11-Suportes para pilhas tipo D, do sistema de iluminação; 12-Suportes para pilhas tipo D, do sistema de exaustão; 15-Lâmpada de atração em linha de centro; Conjunto B - Saco coletor, composto de: $g$-Bocal do tubo coletor; d-Cadarço para isolamento dos insetos capturados; i- Aro de metal para esticar o saco coletor.

luminoso, através da reflexão luminosa difusa inerente à cor branca do corpo da armadilha (Figura 1).

Após a escolha do sítio de captura, a armadilha é exposta, preferencialmente no período vespertino, podendo funcionar durante toda noite, sendo os insetos, geralmente, recolhidos no dia seguinte. Os insetos, atraídos pela luz, são aspirados pela movimentação da hélice e ficam contidos no saco coletor, do qual são retirados com a ajuda de um aspirador bucal ou elétrico.

Teste comparativo entre armadilhas utilizando-se flebotomíneos como modelo. Método. Para verificar a eficiência da armadilha apresentada neste trabalho, utilizamos flebotomíneos (Diptera, Psychodidae), vetores de leishmanioses, como modelo numa área endêmica. Capturas sistemáticas foram realizadas durante três dias consecutivos em cada mês (maio, junho e julho), em 9 locais diferentes, no município de Varzelândia, norte do Estado de Minas Gerais. Armadilhas tipo $\mathrm{CDC}^{5}$ e armadilhas HP foram pareadas no peridomicílio e distanciadas três metros uma da outra. A Tabela 1 mostra 0 resultado comparativo entre as duas armadilhas. Observa-se que as armadilhas CDC capturaram 379 exemplares, enquanto a HP foi capaz de capturar 1.312, aproximadamente quatro vezes mais. Dentre as espécies coletadas pelos dois tipos de armadilhas foram identificadas: Lutzomyia cavernicola $(5,1 \%)$, L evandroi $(0,4 \%)$, L intermedia (5\%), L. ischnacantha $(4,1 \%)$, 
Tabela 1 - Estudo comparativo entre duas armadilhas utilizadas na captura de flebotomíneos. Município de Varzelândia, MG, 2003.

\begin{tabular}{|c|c|c|c|c|c|c|c|c|}
\hline \multirow[b]{2}{*}{ Local } & \multicolumn{2}{|c|}{ mai } & \multicolumn{2}{|c|}{ jun } & \multicolumn{2}{|c|}{ jul } & \multicolumn{2}{|c|}{ Total } \\
\hline & $\mathrm{CDC}$ & $\mathrm{HP}$ & $\mathrm{CDC}$ & $\mathrm{HP}$ & $\mathrm{CDC}$ & $\mathrm{HP}$ & $\mathrm{CDC}$ & $\mathrm{HP}$ \\
\hline Lagoa do Jóia & 12 & 51 & 14 & 11 & 1 & 5 & 27 & 67 \\
\hline Limoeiro & 35 & 324 & 27 & 72 & 0 & 3 & 62 & 399 \\
\hline Campo Redondo & 0 & 0 & 0 & 0 & 0 & 1 & 0 & 1 \\
\hline Tiririca & 8 & 51 & 1 & 5 & 0 & 19 & 9 & 75 \\
\hline Tabual de Cima & 0 & 13 & 4 & 2 & 2 & 11 & 6 & 26 \\
\hline Lagoa de Cima & 36 & 233 & 15 & 65 & 2 & 38 & 53 & 336 \\
\hline Boqueirão da Lagoa & 133 & 139 & 7 & 31 & 21 & 55 & 161 & 225 \\
\hline Erva Doce & 15 & 87 & 31 & 9 & 6 & 72 & 52 & 168 \\
\hline Olhos D’água & 6 & 8 & 2 & 2 & 1 & 5 & 9 & 15 \\
\hline Total & 245 & 906 & 101 & 197 & 33 & 209 & 379 & 1.312 \\
\hline
\end{tabular}

L. lenti (2,1\%), L longipalpis (34,8\%), L. renei $(34,4 \%)$, L. sallesi $(1,7 \%)$, L serrana $(0,1 \%)$, L trinidadensis $(0,1 \%)$ e Lutzomyia spp (12,2\%).

Análise estatística. Os dados obtidos neste estudo foram submetidos ao teste estatístico Mann-Whitney. Houve diferença estatisticamente significativa quando o número total de insetos capturados entre as duas armadilhas foi comparado $(p=0,0386)$ ao nível de confiança de $95 \%$. Os resultados demonstraram que, na área estudada, a armadilha HP mostrouse bastante eficiente podendo ser recomendada em trabalhos de entomologia.

\section{REFERÊNCIAS BIBLIOGRÁFICAS}

1. Chaniotis BN, Anderson JR. Age structure, population dymamics and vector potential of Phlebotomus in Northern California. Journal of Medical Entomology 5: 273-292, 1968.

2. Falcão AR. Um novo modelo de armadilha luminosa de sucção para pequenos insetos. Memórias do Instituto Oswaldo Cruz 76: 303-305, 1981.

3. Lumsden WHR. A trap for insects biting small vertebrates. Nature London 181: 819-820, 1958.

4. Minter DM. A modified Lumsden suction trap for biting insects. Bulletin of Entomological Research 52: 238-240, 1961.

5. Sudia WA, Chamberlain RW. Battery-operated light trap: an improved model. Mosquito News 22: 126-129, 1962. 